\title{
Relationship Between Scale Effect and Structure Levels in Fibrous Structures
}

\author{
NING PAN, SHUMIN ZHAO, and TAO HUA \\ Division of Textiles and Clothing \\ Biological and Agricultural Engineering Department \\ University of California \\ Davis, California 95616
}

\begin{abstract}
A series of testing samples of fibers, yarns, fabrics, and coated fabrics of the same source were prepared and then tested at constant strain rate but different gauge lengths on an Instron tester for tensile test. The results are compared to see the scale effect at different structure levels of fibrous materials. Discussions and explanations of the data are provided as well.
\end{abstract}

\section{INTRODUCTION}

$I^{\mathrm{t}}$ $t$ has long been known that the strength of a material is related to its scale or testing length, and a longer specimen length will yield a value of weaker strength.

This scale effect in textile yarns was first studied by Peirce (22), who proposed the "weakest link" theory to characterize it. The scale effect on composite strength has also grown into a very active area for research with numerous studies being published $(1-3,7-9,11$, $12,15,23-26,29,30)$. Yet, the existence of this effect in fibrous structures seems to have become less certain after some recent theoretical investigations brought ambiguity into the problem. It has become well known that in a fibrous structure under extension, fragmentation may occur (16), prior to the failure of the structure. As a result, the fibers will eventually break into much shorter lengths, better known as the critical length $l_{c}$ at the so called saturated situation, before complete system failure. Therefore, some of the new theories on the strengths of composites $(9$, $13,17,27)$ or textile yarns (18) have predicted that the ultimate strength of a fibrous structure should be calculated by scaling the structure length down to this critical length. The strength thus predicted is closer to the actual value, and higher than the strength calculated based on the original structure length 4 . Yet, according to these theories, the strength of a fibrous structure would be, as claimed by Curtin (8), independent of the structure length or scale, determined chiefly by $l_{c}$ which is generally not related to $l_{f}$.

However, this conclusion is in conflict with some of the experimental findings $(22,30)$. Zweben (30) has listed many results as evidence for a scale effect. Also he has explored the reasons why the scale effect in composites has not been widely recognized and the implications of the scale effect for composite applications.

Also, other more detailed analyses $(3,6-9,24,25)$ predict the existence of the scale effect in fibrous structures especially in fiber reinforced composites.

It is therefore the purpose of this study to further investigate the issue of scale effect experimentally of fibrous structures. We will examine the existence of the scale effect in fibrous structure at different structural levels, and explain the differences of scale effect on the tensile properties of fibers, yarns, fabrics, and coated fabrics so as to validate some of the new theories.

\section{FIBER AND BUNDLE STRENGTHS}

The following is a brief summary of the theoretical account of the problem presented by Pan et al. (19).

It has been widely accepted that for brittle fibers such as glass, ceramic, carbon, and some polymer fibers (21), the strength cumulative probability distribution obeys the Weibull function (28). Consequently, for a fiber of length $l_{f}$, the mean or the expected value of the fiber strength $\overline{\sigma_{f}}$ can then be calculated according to Colman (5) as

$$
\overline{\sigma_{f}}=\left(l_{f} \alpha\right)^{-\frac{1}{\beta}} \Gamma\left(1+\frac{1}{\beta}\right)
$$

where $\Gamma()$ is the Gamma function, and the standard deviation of the strength is

$$
\Theta_{f}=\bar{\sigma}_{f}\left(\frac{\Gamma\left(1+\frac{2}{\beta}\right)}{\Gamma^{2}\left(1+\frac{1}{\beta}\right)}-1\right)^{\frac{1}{2}}
$$


where $\alpha$ is the scale parameter and $\beta$ is the shape parameter of the fiber and both are independent of the fiber length $l_{5}$. The shape parameter $\beta$ is an indicator of the fiber strength variation. A higher $\beta$ value corresponds to a lower variance, and when $\beta \rightarrow \infty$, the fiber variation would approach zero and its strength would become independent of its length.

Then according to Daniels (10), for a fibrous system where $N$ fibers form a parallel bundle with no interaction between individual fibers, the density distribution function of the bundle strength $\sigma_{p}$ approaches a normal form so the expected value of the bundle strength $\overline{\sigma_{p}}$ is

$$
\overline{\sigma_{p}}=\left(l_{f} \alpha \beta\right)^{-\frac{1}{\beta}} \exp \left(-\frac{1}{\beta}\right)
$$

and the standard deviation of the strength $\Theta_{p}$ is

$$
\Theta_{p}^{2}=\left(l_{f} \alpha \beta\right)^{-\frac{2}{\beta}}\left[\exp \left(-\frac{1}{\beta}\right)\right]\left[1-\exp \left(-\frac{1}{\beta}\right)\right] \cdot N^{-1}
$$

In Daniels' analysis, however, it is assumed that when a fiber breaks, the load it was carrying is instantaneously shared equally among all the surviving fibers (the so-called global load-sharing model) so that neither stress concentration nor dynamic wave propagation effects are considered.

It is well recognized that the expected strength of a fiber bundle is lower than that of the fiber by a factor $\Phi$, which is the ratio of Equations 1 and 3 and is sometimes called the "Coleman factor" (4)

$$
\Phi=\frac{\overline{\sigma_{f}}}{\overline{\sigma_{p}}}=(\beta)^{\frac{1}{\beta}} \exp \left(\frac{1}{\beta}\right) \Gamma\left(1+\frac{1}{\beta}\right)
$$

The standard deviation of the strength of the fiber bundie is also smaller, depending among other factors on $N$, than that of the fiber given in Equation 2.

\section{THE STRENGTH OF A YARN STRUCTURE}

According to Pan (18), if a twisted filament yarn is treated as a chain of twisted fiber bundles of critical length $l_{c}$, building upon the above theoretical results, the expected strength $\bar{\sigma}_{y}$ for the yarn can be finally expressed as

$$
\overline{\sigma_{y}}=\eta_{q} V_{f}\left(l_{c} \alpha \beta\right)^{-\frac{1}{\beta}} \exp \left(-\frac{1}{\beta}\right)
$$

where $V_{f}$ is the fiber-volume fraction in the yarn, and $\eta_{q}$ is the so-called orientation efficiency factor reflecting the fact that fibers in a twisted yarn are oriented in various directions instead of being parallel to the yarn axis. This factor is a function of $q$ where $q$ is the fiber helix angle at the yarn surface.

The critical length $l_{c}$ is also given by Pan (18). If $\sigma_{f b}$ is the tensile stress that causes the fiber to break, it follows that

$$
l_{c}=\frac{r_{f} \sigma_{f b}}{\mu g}
$$

where $r_{f}$ is the fiber radius, $\mu$ is the frictional coefficient between fibers and $g$ the local lateral pressure.

Although not affecting our study, it should be mentioned that Equation 7 is a rather crude method of defining the critical length, since fiber strength is actually random and fragmentation involves the socalled exclusion zone effect. This issue is reviewed in Hui et al. (14), where the need for a correction factor and a method for calculating it is discussed.

\section{THE STRENGTH OF A FABRIC STRUCTURE}

The expected uniaxial tensile strength of a fabric sample is, according to Pan (20), a complex function of both yarn strength and yarn-yarn interactions

$$
\overline{\sigma_{F}}=f\left(\overline{\sigma_{y}}, l_{c f}\right)
$$

where $\overline{\sigma_{y}}$ is the expected yarn strength, $l_{c f}$ is the critical length reflecting the yam-yam interactions and in this case

$$
L_{c f}=\left[\frac{1}{C_{y} n_{y} \tau_{y}}\left(\frac{4}{3} \alpha_{y}\right)^{-\frac{1}{\beta_{s}}}\left(1+\frac{1}{\beta_{y}}\right)\right]^{1+\frac{\beta_{\alpha}}{1+\theta_{v}}}
$$

where $C_{y}$ represents the length of the yarn-yarn contact area. $n_{y}$ is the number of yarns per fabric length; $\tau_{y}$ is the shear resistance or the interfacial strength at the yarn contact area; and $\alpha_{y}$ and $\beta_{y}$ are the Weibull scale and shape parameters of the yarn.

\section{TAE STRENGTH OF A COATED FABRIC STRUCTURE}

The strength of a coated fabric is similar to that of an uncoated fabric except that the interfacial strength $\tau_{y}$ is greater for a coated fabric structure because of the effect of the coating agent, which will also make the fabric structurally more uniform.

\section{THE SCALE EPFECT IN FIBROUS STRUCTURES}

It is clear now theoretically from Equations $I$ and 9 that the critical length will have different values for different structures. Also, for a given structure, the strength is determined in ideal case by the critical length, and is independent of the original testing length.

First in the case of single fiber whose strength is a function of its length $l_{f}$ as indicated in Equation 1, its strength therefore changes as a function of the length

$$
\frac{d \sigma_{f}}{d l_{f}}=\frac{-\alpha\left(l_{f} \alpha\right)^{-1-\frac{1}{\beta}} \Gamma\left(1+\frac{1}{\beta}\right)}{\beta}
$$

Then for the fiber bundle, we still have

$$
\frac{d \sigma_{p}}{d l_{f}}=\frac{-\alpha\left(l_{f} \beta \alpha\right)^{-1-\frac{1}{\beta}}}{\exp \left(-\frac{1}{\beta}\right)}
$$


Between Scale Effect and Structure Levels

Table 1. Specifications of Samples.

\begin{tabular}{|c|c|c|c|c|c|}
\hline No. & fiber content & weave & $\begin{array}{l}\text { fabric count } \\
\text { warp } \times \text { weft } \\
(\mathrm{No} / 2.54 \mathrm{~cm})\end{array}$ & $\begin{array}{l}\text { yarn number } \\
\text { warp } \times \text { weft } \\
\text { (tex) }\end{array}$ & $\begin{array}{c}\text { fabric weight } \\
\qquad g / m^{2}\end{array}$ \\
\hline $\begin{array}{l}1 \\
2 \\
3 \\
4 \\
5\end{array}$ & $\begin{array}{l}100 \% \text { Nomex } \\
60 \% \text { Kevlar } / 40 \% \text { PBI } \\
100 \% \text { Nylon (coated) } \\
100 \% \text { Polyester } \\
100 \% \text { Polyester(coated) }\end{array}$ & $\begin{array}{l}\text { plain } \\
\text { twill } \\
\text { plain } \\
\text { plain } \\
\text { plain }\end{array}$ & $\begin{array}{l}65 \times 45 \\
67 \times 55 \\
49 \times 36 \\
65 \times 45 \\
68 \times 44\end{array}$ & $\begin{array}{l}33.1 \times 36.3 \\
45.5 \times 44.29 \\
34.3 \times 31.2 \\
31.3 \times 32.4 \\
32.5 \times 33.4\end{array}$ & $\begin{array}{l}202.3 \\
153.3 \\
240.2 \\
134.4 \\
237.4\end{array}$ \\
\hline
\end{tabular}

So, in general, the strength of a fiber bundle is still dependent on the fiber length, except that when the number of fibers approach to infinity, so that the variability in strength goes to zero in Equation 4, then the bundle strength becomes independent of the fiber length.

Now if we turn to the cases of yarn, fabric, and coated fabric, their strengths are dependent on the critical length of various values due to fragmentation process, and the derivatives of strength to the original length will be zero. Therefore, in ideal situation, the strengths of these structures should be independent of the original lengths.

However, in practical cases, it is not inevitable for the fragmentation process to occur or to reach saturation so as for the structures to break at their corresponding critical length values. In general, the greater the structural constraint to the component, the more likely a structure will break at the critical length.

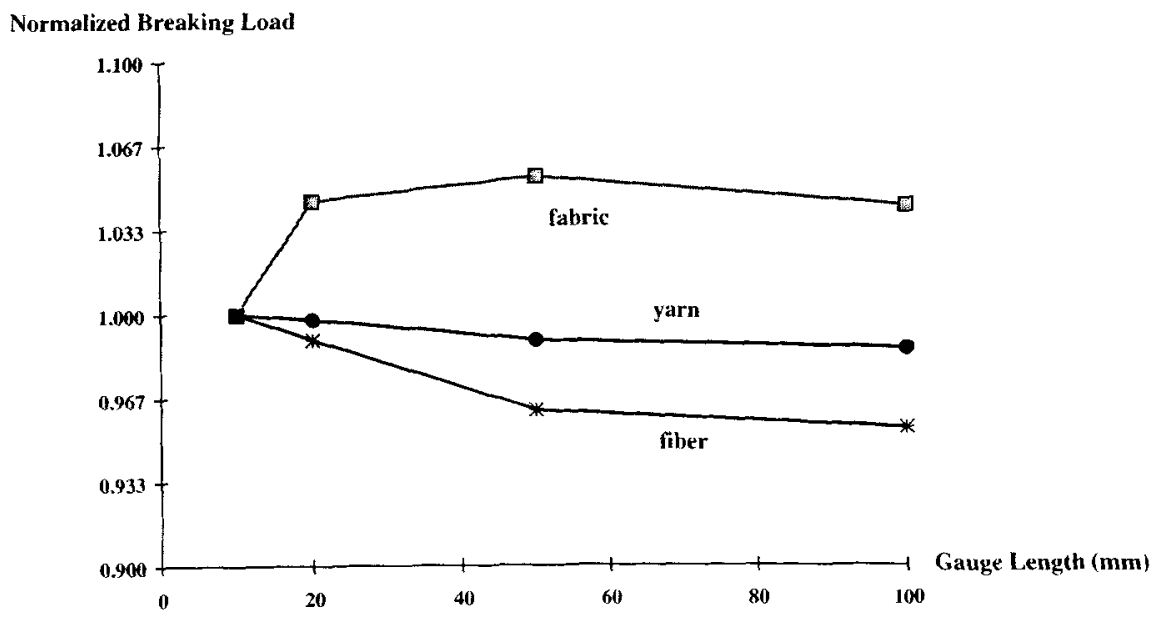

(a)

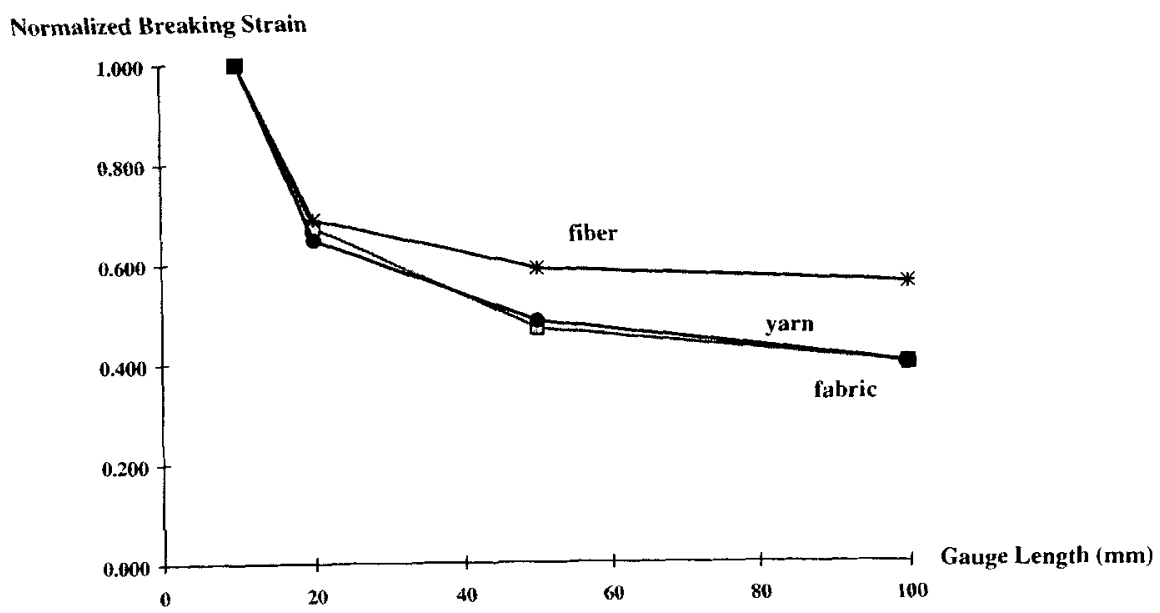

(b)

Fig. 1. Testing gauge length versus the property for fabric 4: (a) Normalized breaking load; (b) Normalized breaking strain. 
Table 2a. Tensile Testing Properties and Their SD Values for Fabric 1.

\begin{tabular}{|c|c|c|c|c|}
\hline gauge length $(\mathrm{mm})$ & 10 & 20 & 50 & 100 \\
\hline $\begin{array}{l}\text { fabric } \\
\text { breaking load }(\mathrm{N}) \\
\text { breaking strain }(\%)\end{array}$ & $\begin{array}{ll}554.9 & (25.2) \\
190.4 & (15.2) \\
\end{array}$ & $\begin{array}{ll}594.4 & (11.5) \\
116.0 & (5.95) \\
\end{array}$ & $\begin{array}{rr}594.8 & (14.7) \\
74.2 & (2.76) \\
\end{array}$ & $\begin{array}{rr}569.6 & (15.2) \\
57.0 & (1.34) \\
\end{array}$ \\
\hline $\begin{array}{l}\text { yarn } \\
\text { breaking load }(\mathrm{N}) \\
\text { breaking strain }(\%)\end{array}$ & $\begin{array}{l}10.36(0.92) \\
77.17(6.39)\end{array}$ & $\begin{array}{l}10.17(1.79) \\
57.20(5.05)\end{array}$ & $\begin{array}{r}9.96(1.14) \\
47.50(5.38)\end{array}$ & $\begin{array}{r}9.40(1.11) \\
40.17(5.34)\end{array}$ \\
\hline
\end{tabular}

Table 2b. Normalized Tensile Properties for Fabric 1.

\begin{tabular}{lcccc}
\hline gauge length $(\mathbf{m m})$ & 10 & 20 & 50 & 100 \\
\hline $\begin{array}{l}\text { fabric } \\
\text { breaking load }\end{array}$ & 1.000 & 1.071 & 1.072 & 1.027 \\
breaking strain (\%) & 1.000 & 0.609 & 0.390 & 0.299 \\
\hline $\begin{array}{l}\text { yarn } \\
\text { breaking load }\end{array}$ & & & & \\
breaking strain (\%) & 1.000 & 0.982 & 0.961 & 0.907 \\
\hline
\end{tabular}

Furthermore, the closer the structure reaches the saturation of the fragmentation, the less the scale effect. Therefore, for single fiber test, since there is no constraint from other fibers, there will be no fragmentation process takes place; the single fiber case will hence show the most significant scale effect. Whereas in the case of yarn, fibers are constrained by the neighboring fibers, so there will be some fragmentation process occuring. For fabrics, the fibers are con-

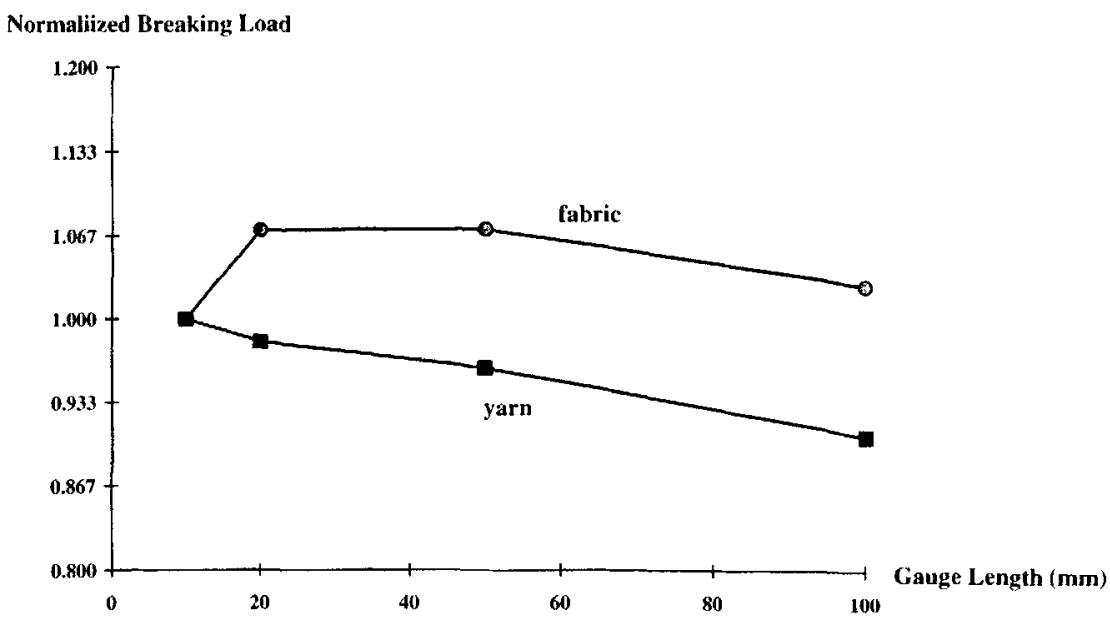

(a)

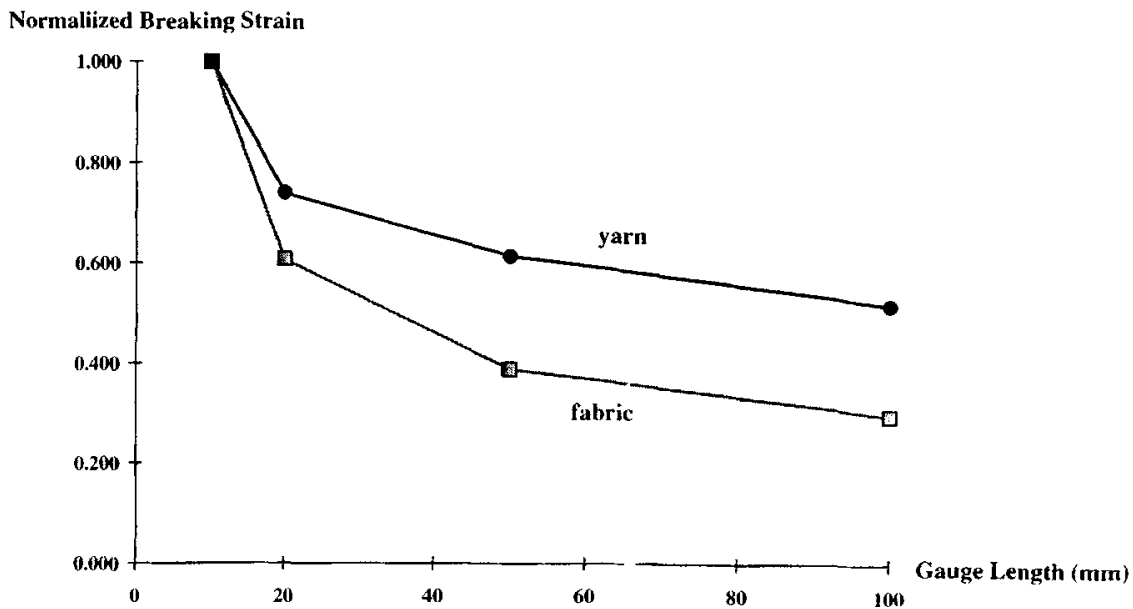

(b)

Fig. 2. Testing gauge length versus the property for fabric 1: (a) Normalized breaking load; (b) Normalized breaking strain. 
Between Scale Effect and Structure Levels

Table 3a. Tensile Testing Properties and Their SD Values for Fabric 2.

\begin{tabular}{|c|c|c|c|c|}
\hline gauge length $(\mathrm{mm})$ & 10 & 20 & 50 & 100 \\
\hline $\begin{array}{l}\text { yarn } \\
\text { breaking load }(\mathrm{N}) \\
\text { breaking strain }(\%)\end{array}$ & $\begin{array}{l}10.62(1.52) \\
22.08(1.72)\end{array}$ & $\begin{array}{l}10.55(1.63) \\
13.36(1.67)\end{array}$ & $\begin{array}{l}9.81(1.43) \\
9.63(0.98)\end{array}$ & $\begin{array}{l}8.93(1.24) \\
8.40(0.78)\end{array}$ \\
\hline
\end{tabular}

Table 3b. Normalized Tensile Properties for Fabric 2.

\begin{tabular}{lcccc}
\hline gauge length $(\mathbf{m m})$ & 10 & 20 & 50 & 100 \\
\hline fabric & & & & \\
breaking load & 1.000 & 1.104 & 1.114 & 1.126 \\
breaking strain $(\%)$ & 1.000 & 0.608 & 0.374 & 0.292 \\
\hline yarn & & & & \\
breaking load & 1.000 & 0.993 & 0.924 & 0.841 \\
breaking strain $(\%)$ & 1.000 & 0.659 & 0.475 & 0.414 \\
\hline
\end{tabular}

fined by the surrounding fibers and the fibers as a whole (yarns) are in turn constrained by other yarns in contact in the fabric, and these double actions will enhance the fragmentation process. Lastly, in the case of coated fabrics, the coating agent will add an additional binding to the fibers to reinforce the fragmentation process. So we can predict here that the ranking in terms of the scale effect will be single fiber $>$ yarn $>$ fabric $>$ coated fabric.

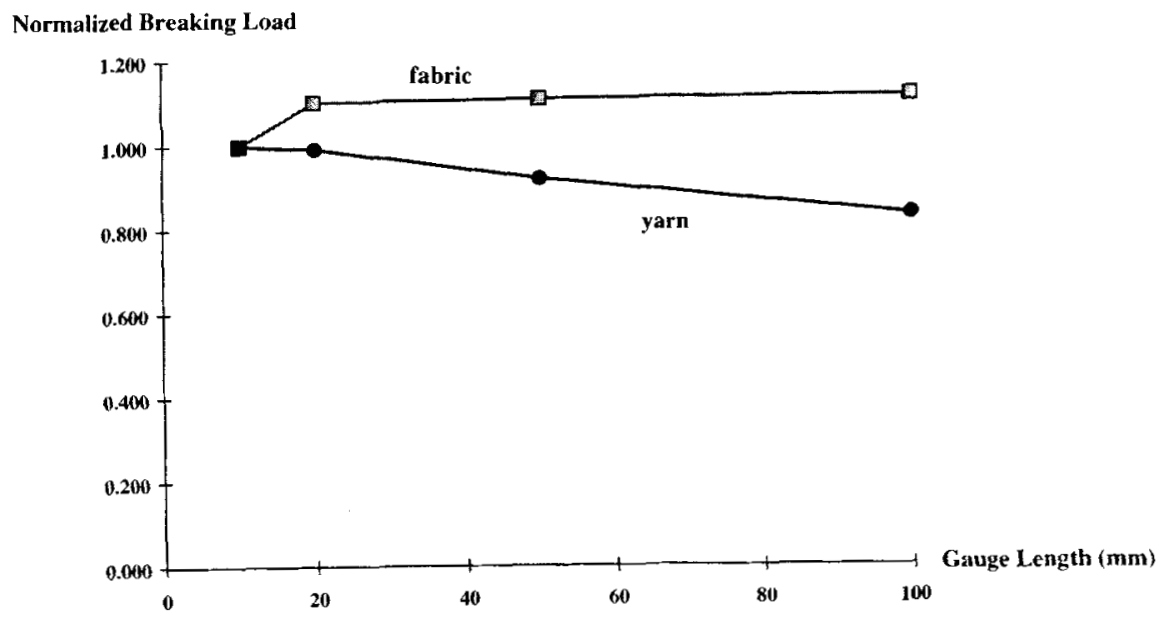

(a)

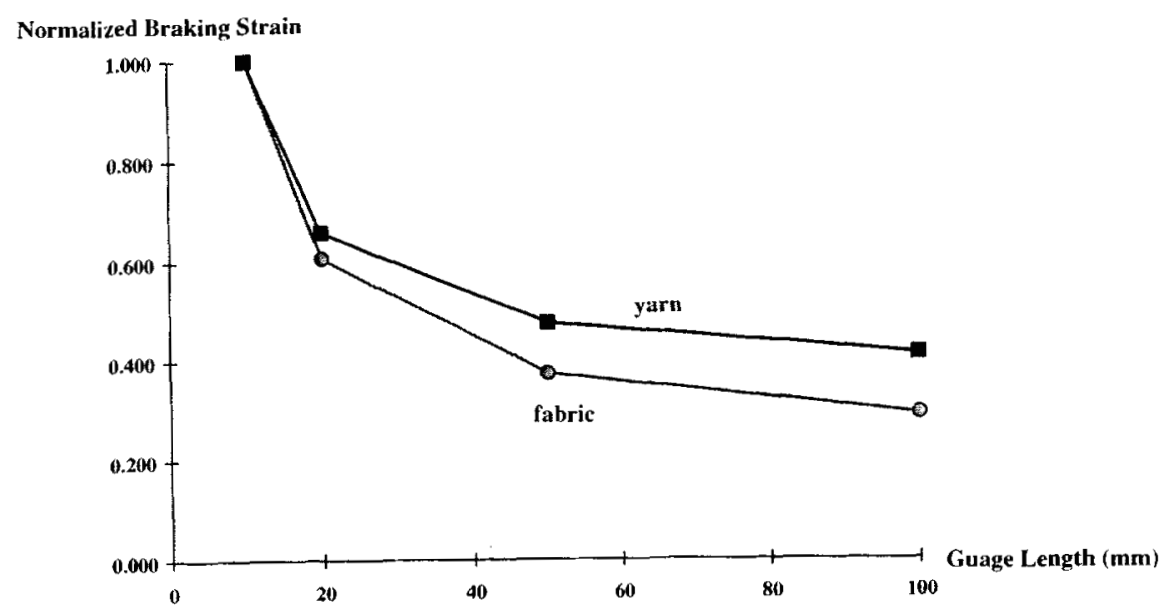

(b)

Fig. 3. Testing gauge length versus the property for fabric 2: (a) Normalized breaking load; (b) Normalized breaking strain. 
Ning Pan, Shumin Zhao, and Tao Hua

Table 4a. Tensile Testing Properties and Their SD Values for Fabric 3.

\begin{tabular}{lccrr}
\hline gauge length $(\mathrm{mm})$ & 10 & 20 & 50 & 100 \\
\hline fabric & & & $682.6(13.1)$ & $691.3(15.4)$ \\
breaking load $(\mathrm{N})$ & $646.4(10.1)$ & $674.4(18.9)$ & $43.86(2.16)$ \\
breaking strain $(\%)$ & $100.5(5.84)$ & $67.55(3.25)$ & & $37.44(3.47)$ \\
\hline yarn & & & $15.11(1.43)$ & $16.44(1.26)$ \\
breaking load $(\mathrm{N})$ & $15.47(1.51)$ & $15.80(1.22)$ & $19.80(2.06)$ & $20.24(1.60)$ \\
breaking strain $(\%)$ & $32.35(8.52)$ & $23.64(2.14)$ & & \\
\hline
\end{tabular}

Table 4b. Normalized Tensile Properties for Fabric 3.

\begin{tabular}{lcccc}
\hline gauge length $(\mathbf{m m})$ & $\mathbf{1 0}$ & $\mathbf{2 0}$ & $\mathbf{5 0}$ & $\mathbf{1 0 0}$ \\
\hline fabric & & & & \\
breaking load & 1.000 & 1.043 & 1.056 & 1.069 \\
breaking strain $(\%)$ & 1.000 & 0.672 & 0.436 & 0.373 \\
\hline yam & & & & \\
breaking load & 1.000 & 1.023 & 0.977 & 1.041 \\
breaking strain (\%) & 1.000 & 0.731 & 0.612 & 0.626 \\
\hline
\end{tabular}

Also, some of the recent new theories $(3,6-9,24,25)$ indicate that when a fiber in a structure breaks, the load sharing process is far from global; depending on the bonding strength, the load sharing can be very local. In other words, the fiber structure breaks in a characteristic fiber bundle whose size is dependent on fiber matrix bonding strength. This local load sharing not only predicts the existence of the scale effect but leads to different scale effect at various structural levels in fibrous structures especially in fiber reinforced composites.

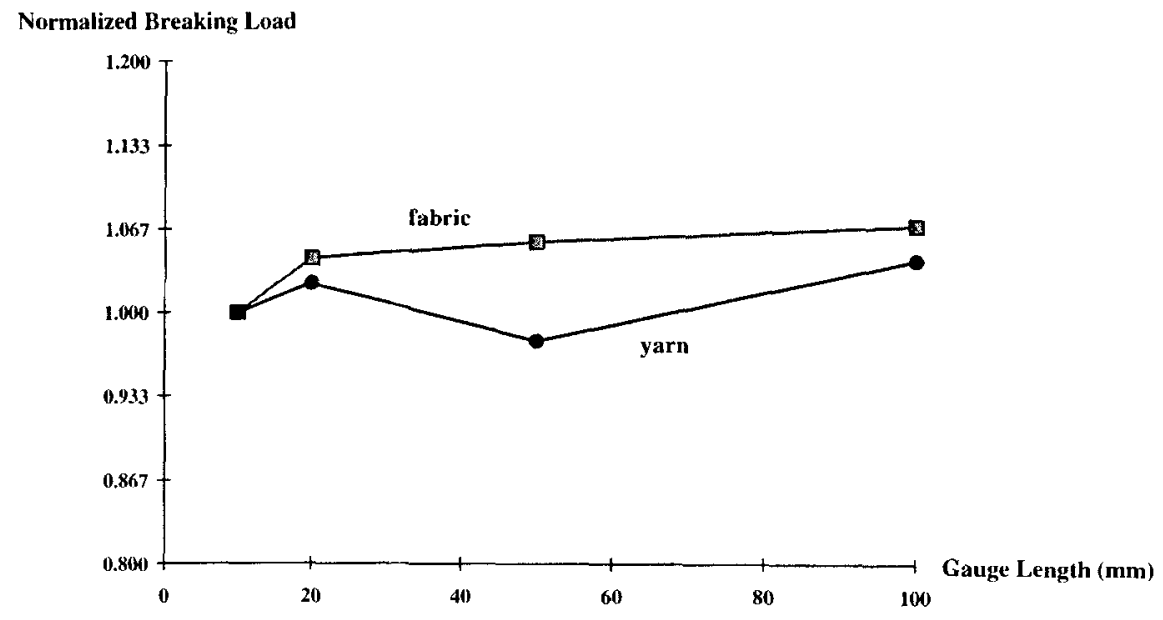

(a)

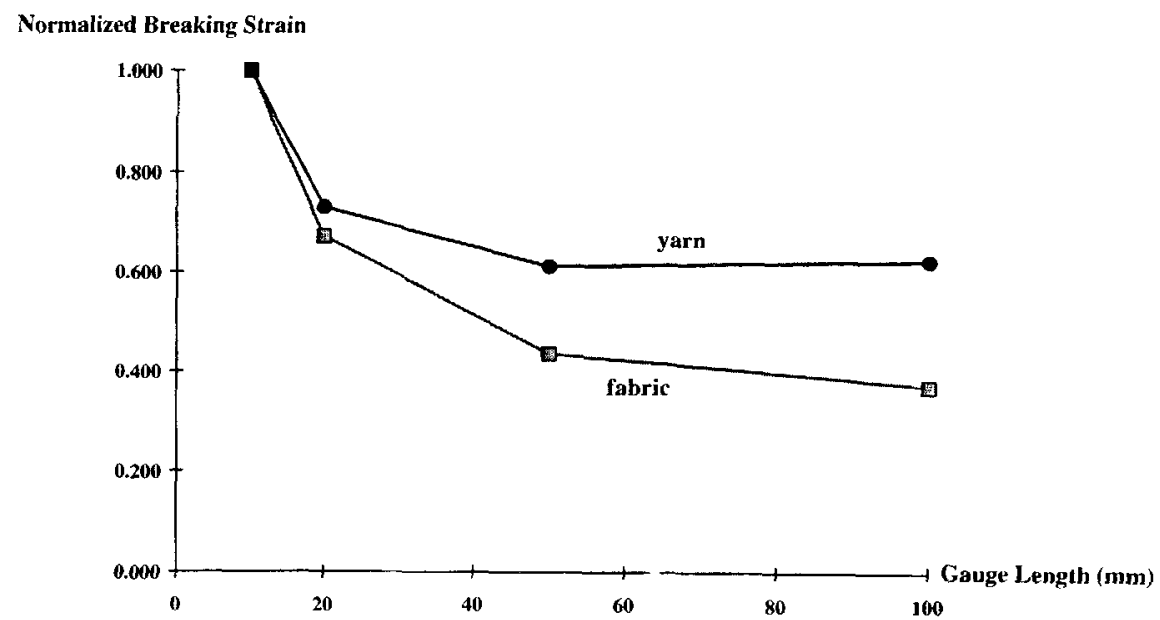

(b)

Fig. 4. Testing gauge length versus the property for fabric 3: (a) Normalized breaking load; (b) Normalized breaking strain. 


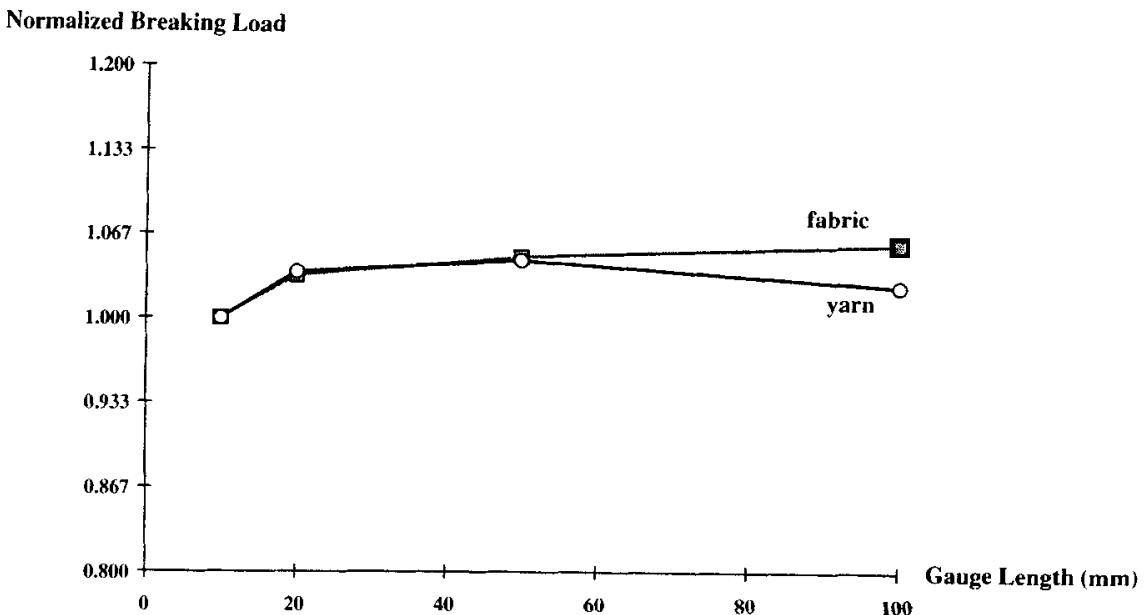

(a)

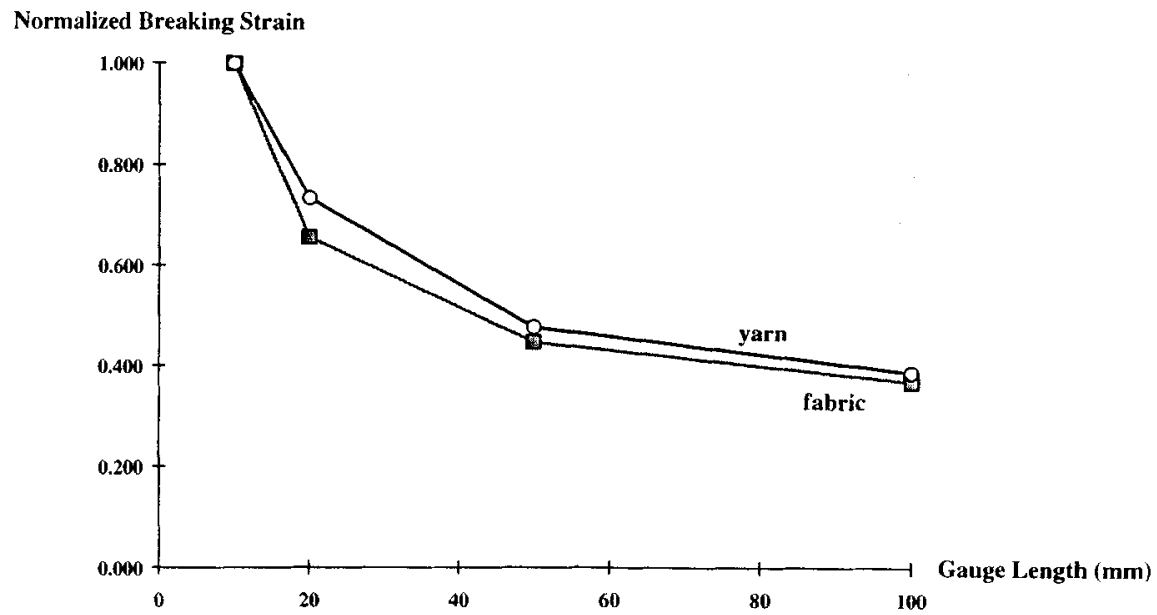

(b)

Fig. 5. Testing gauge length versus the property for fabric 5: (a) Normalized breaking load; (b) Normalized breaking strain.

\section{EXPERTMENTAL}

Five fabric samples are selected for verification of the above predictions. Among these five fabrics, two are coated using neoprene of $0.076 \mathrm{~mm}$ thickness on the back side for waterproofing. Detailed descriptions of the samples are provided in Table 1.

For all fabrics, yarn samples were unraveled from the fabric, except in the case of fabric sample 4 from which both yarn and single fibers are unraveled because it is made of continuous filament fibers and is possible to unravel to the fiber level. So we can in principle have three different structural levels, i.e., fabrics, yarns from the fabric and fibers from the yarns. For other fabric samples, we can only unravel into yarns. Four different gauge lengths $-10 \mathrm{~mm}, 20$ $\mathrm{mm}, 50 \mathrm{~mm}$, and $100 \mathrm{~mm}$ - were chosen to examine the testing length effect; correspondingly, testing extending speed $10 \mathrm{~mm} / \mathrm{min}, 20 \mathrm{~mm} / \mathrm{min}, 50 \mathrm{~mm} / \mathrm{min}$, and $100 \mathrm{~mm} / \mathrm{min}$ were used respectively so that the strain rate of the specimen remained constant $(100 \%$ strain/min). For the fabric specimens, the width is the standard $2.54 \mathrm{~mm}$, and the dimension for yarns are shown in Table 1. All the tests were carried out carefully at given gauge lengths so that no sample slippage or pre-damage was observed.

The samples were tested on an Instron strength tester at the standards atmospheric condition of $65 \%$ $\mathrm{RH}$ and $70 \mathrm{~F}^{\circ}$ temperature after the samples had been conditioned at the conditions to reach the atmospheric equilibrium. Each data point is the average of 30 , 20 , and 10 tests for single fiber, yarn and fabric specimens, respectively.

\section{RESULTS AND DISCUSSION}

The breaking loads and breaking strains of the samples were determined as shown in Tables $2 a$ for sample $1,3 a$ for sample $2,4 a$ for fabric 3 , and $5 a$ for fabric 4 , and $6 a$ for fabric 5 . 
Table 5a. Tensile Testing Properties and Their SD Values for Fabric 4.

\begin{tabular}{|c|c|c|c|c|}
\hline gauge length $(\mathrm{mm})$ & 10 & 20 & 50 & 100 \\
\hline $\begin{array}{l}\text { fabric } \\
\text { breaking load }(\mathrm{N}) \\
\text { breaking strain }(\%)\end{array}$ & $\begin{array}{rr}632.1 & (30.3) \\
58.96 & (6.32) \\
\end{array}$ & $\begin{array}{l}\beta=43.27 \\
660.5(17.9) \\
39.69(2.71)\end{array}$ & $\begin{array}{r}666.9(11.2) \\
27.74(1.78)\end{array}$ & $\begin{array}{r}660.0(25.2) \\
23.63(1.44)\end{array}$ \\
\hline $\begin{array}{l}\text { yarn } \\
\text { breaking load }(\mathrm{N}) \\
\text { breaking strain }(\%)\end{array}$ & $\begin{array}{l}13.09(0.18) \\
78.2 \quad(3.74)\end{array}$ & $\begin{array}{l}\beta=49.16 \\
13.07(0.34) \\
50.7 \quad(3.78) \\
\end{array}$ & $\begin{array}{l}12.96(0.17) \\
37.9 \quad(1.88)\end{array}$ & $\begin{array}{l}12.92(0.25) \\
31.45(1.69)\end{array}$ \\
\hline $\begin{array}{l}\text { fiber } \\
\text { breaking load }(\mathrm{N}) \\
\text { breaking strain }(\%)\end{array}$ & $\begin{array}{cc}.2866 & (.0105) \\
47.89 \quad(4.57)\end{array}$ & $\begin{array}{c}\beta=25.76 \\
.2838(.0126) \\
33.02 \quad(4.20)\end{array}$ & $\begin{array}{cc}.2757(.0114) \\
28.26 \quad(3.82)\end{array}$ & $\begin{array}{cc}.2736 & (.0119) \\
26.95 \quad(2.35)\end{array}$ \\
\hline
\end{tabular}

Table 5b. Normalized Tensile Properties for Fabric 4.

\begin{tabular}{lcccc}
\hline gauge length $(\mathbf{m m})$ & 10 & $\mathbf{2 0}$ & $\mathbf{5 0}$ & $\mathbf{1 0 0}$ \\
\hline $\begin{array}{l}\text { fabric } \\
\text { breaking load }\end{array}$ & 1.000 & 1.045 & 1.055 & 1.044 \\
breaking strain (\%) & 1.000 & 0.673 & 0.470 & 0.401 \\
\hline yarn & & & & \\
$\begin{array}{l}\text { breaking load } \\
\text { breaking strain (\%) }\end{array}$ & 1.000 & 0.998 & 0.990 & 0.987 \\
\hline $\begin{array}{l}\text { fiber } \\
\text { breaking load }\end{array}$ & 1.000 & 0.648 & 0.485 & 0.402 \\
\hline breaking strain (\%) & 1.000 & 0.990 & 0.962 & 0.955 \\
\hline
\end{tabular}

For easy comparison, we also normalized all the data by dividing them by the values measured at 10 mm gauge length. The corresponding results are in Tables $b$.

According to the data, the fabrics can be classified into several groups. First, we plot the data in Table $5 b$ for fabric 4 in three cases of fabric, yarn and fiber in Figure 1. It is seen in Figure $1 a$ that the normalized breaking load for fiber decreases significantly as we increase the gauge length. The yarn load also declines with gauge length but not as steep as the fiber. The fabric load on the other hand somehow increases at longer gauge length for reasons to be further explored. Nevertheless, we can conclude here the scale effect indeed exists and is different at different structural levels.

The existence of this difference between different structural levels can only be attributed to the fragmentation process, the load sharing and the critical length theory introduced before. In the ideal situation, there should be no scale effect for both yarn and fabric. However, since in practice, the fragmentation process rarely reaches the saturation stage and the load sharing is always not global so that the fragments are still longer than the theoretical critical length and also with some variations in length which lead to the scale effect on yarn and fabric.

On the other hand, although the breaking strains in Table $5 b$ also reduce at longer gauge length as seen in Figure $1 b$, the reduction is the highest in fabric, then yarn, and fiber has the least change; a trend just opposite to the case of breaking load. This is an interesting and important issue worth further studying.
Judging from the shape parameter $\beta$ value of the breaking load in Table 5a, and a smaller $\beta$ value representing a more brittle material (4), fiber seems to be the most brittle; the yarn formed by twisting fibers together is most extensible. The fabric formed by interlacing yarns in two perpendicular directions is in between in terms of extensibility.

By plotting uncoated fabrics 1 , and 2 whose data are in Tables $2 b, 3 b$ in Figures 2 and 3 , similar conclusions can be reached that the gauge length has different effect on fabric and yarn, and the effect is in opposite trends for both breaking load and strain cases.

As to the coated fabrics 3 and 5 , although we can still see similar pattern of scale effect in Figures 4 and 5 , the differences in breaking load and strain between fabric and yarn more or less reduce, presumably because of the existence of the coating agent. In other words, as expected the coating agent makes the materials more uniform so that they become less sensitive to gauge length changes.

Moreover, when we determined the Weibull Shape parameter $\beta_{y}$ of the breaking load with and without coating for yarns of fabrics 5 using the data at gauge length $20 \mathrm{~mm}$, we found that $\beta_{y}=31.53$ for yarns without coating and $\beta_{y}=22.56$ for yarns with coating. This indicates that after the coating finish, the yarns become less extensible.

\section{- Conclusions}

of the fiber, yarn and fabric samples, in general gauge length effect on breaking load is most significant at fiber level, less so in yarn level and has a somehow enhancing effect at fabric level because of the existence of the load-sharing and fragmentation process. However, this trend is completely reversed in the breaking strain case.

Judging from the Weibull Shape parameter $\beta$, if single fiber behaves as a brittle material, then the yarn made from the fiber is more extensible, and the fabric from the yarns are in between.

The coating agent makes the materials more uniform so that they become less sensitive to gauge length changes, and coating also makes the samples less extensible. 
Table 6a. Tensile Testing Properties and Their SD Values for Fabric 5.

\begin{tabular}{lcccc}
\hline gauge length $(\mathbf{m m})$ & 10 & 20 & 50 & 100 \\
\hline fabric & & & & \\
breaking load $(\mathrm{N})$ & $751.2(19.5)$ & $776.7(14.5)$ & $789.1(12.0)$ & $798.0(16.9)$ \\
breaking strain $(\%)$ & $64.83(5.33)$ & $42.61(2.14)$ & & $29.14(0.98)$ \\
\hline yarn & & & & $24.03(1.04)$ \\
breaking load $(\mathrm{N})$ & $13.07(0.32)$ & $13.56(0.35)$ & $13.69(0.36)$ & $13.43(0.48)$ \\
breaking strain $(\%)$ & $70.48(7.80)$ & $51.80(5.48)$ & $33.74(3.04)$ & $27.49(2.82)$ \\
\hline
\end{tabular}

Table 6b. Normalized Tensile Properties for Fabric 5.

\begin{tabular}{lcccc}
\hline gauge length $(\mathbf{m m})$ & $\mathbf{1 0}$ & $\mathbf{2 0}$ & $\mathbf{5 0}$ & $\mathbf{1 0 0}$ \\
\hline $\begin{array}{l}\text { fabric } \\
\text { breaking load }\end{array}$ & 1.000 & 1.034 & 1.050 & 1.062 \\
breaking strain $(\%)$ & 1.000 & 0.657 & 0.449 & 0.371 \\
\hline yarn & & & & \\
breaking load & 1.000 & 1.037 & 1.047 & 1.028 \\
breaking strain (\%) & 1.000 & 0.735 & 0.479 & 0.390 \\
\hline
\end{tabular}

\section{ACKNOWLEDGMENT}

The authors would like to thank the Fabri Cote Company and the North Face Company for providing the samples used in this study.

\section{REFERENCES}

1. Z. P. Bazant, Z. Z. Li, and M. Thoma, J. Engineering Mechanics-ASCE, 121, 620 (1995).

2. Z. P. Bazant and R. Desmorat, J. Engineering Mechanics -ASCE, 120,1945 (1994)

3. I. J. Beyerlein and S. L. Phoenix, Composites Science and Technology, 56, 75 (1996).

4. T. W. Chou, Microstructural Design of Fiber Composites, Cambridge University Press, Cambridge, England (1992).

5. B. D. Colman, J. Mech. Phys. Solids, 7, 60 (1958).

6. W. A. Curtin, J. Mech. Phys. Solids, 41, 217 (1993).

7. W. A. Curtin, Polym. Compos., 15, 474 (1994).

8. W. A. Curtin, J. American Ceramic Society, 77, 1072 (1994).

9. W. A. Curtin, J. American Ceramic Society, 74, 2837 (1991).
10. H. E. Daniels, Proc. Roy. Society, A183, 405 (1945),

11. M. R. Gurvich and R. B. Pipes, Composites Sci. Tech., 55, 93 (1995).

12. D. G. Harlow and S. L. Phoenix, J. Mechanics and Physics of Solids, 39, 173 (1991).

13. C. Y. Hui, S. L. Phoenix, M. Ibnabdeljalil, and R. L. Smith, J. Mechanics and Physics of Solids, 43, 1551 (1995).

14. C. Y. Hui, S. L. Phoenix, and D. Shia, Composites Sci. Tech. 57, 1707 (1997).

15. M. Ibnabdeljalil and S. L. Phoenix, Acta Metallurgica et Materialia, 43, 2975 (1995).

16. C. J. Monego and S. Backer, Textile Res. J., 38, 762 (1968)

17. A. N. Netravali, R. B. Henstenburg, S. L. Phoenix, and P. Schwarts, Polym. Compos., 10, 226 (1989).

18. N. Pan, J. Material Science, 28, 6107 (1993).

19. N. Pan, H. C. Chen, J. Thompson, M. K. Inglesby, and S. H. Zeronian. J. Material Science, 33, 2667 (1998).

20. N. Pan, Composite Science and Technology, 56, 311 (1996).

21. N. Pan, H. C. Chen, J. Thompson, M. K. Inglesby, S. Khatua, X. S. Zhang, and S. H. Zeronian, J. Materials Science, 32, 2677 (1997)

22. F. T. Peirce, J. Text. Inst., 17, 355 (1926).

23. H. J. Phillips, R. A. Shenoi, and S. M. Lewis, Materials Sci Letters, 21, 229 (1994).

24. S. L. Phoenix and R. Raj, Acta Metallurgica et Materialia, 40, 2813 (1992).

25. S. L. Phoenix, M. Ibnabdeljalil, and C. Y. Hui, International J. Solids and Structures, 34, 545 (1997).

26. V. B. Sapozhnikov and M. G. Goldiner, J. Physics AMathematical and General, 23, 5309 (1990).

27. H. R. Schweitert and P. S. Steif, Int. J. Solid Struct., 28 , 283 (1991).

28. W. Weibull, J. Appl. Mech, 18, 293 (1951).

29. Y. W. Zeng and S. Meriani, J. Applied Crystallography, 27, 782 (1994).

30. C. Zweben, Composites, 25, 451 (1994). 